\title{
Aveiro: cidade amiga das pessoas idosas!?
}

\author{
Avera anagefriendyaity!?
}

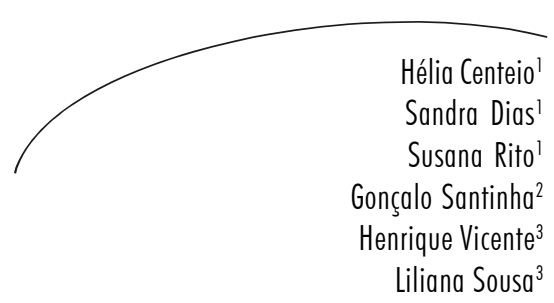

Resumo

A Organização Mundial de Saúde (OMS) lançou a iniciativa Age-Friendly Cities para mobilizar as cidades do mundo na promoção do envelhecimento ativo. Respondendo a esse desafio, este estudo procura compreender como a cidade de Aveiro (Portugal) é ou não amiga das pessoas idosas. A metodologia seguiu o protocolo de Vancouver, proposto pela OMS. A entrevista de coleta de dados solicita aos participantes que identifiquem aspectos positivos e negativos da cidade e indiquem sugestões nos seguintes tópicos: espaços exteriores e edifícios; transportes; habitação; respeito e inclusão social; participação social; comunicação e informação; participação cívica e emprego; apoio comunitário e serviços de saúde. A entrevista foi aplicada em

Palavras-chave: Cidades. Envelhecimento. Idosos. Participação. grupos focais a uma amostra de 37 pessoas idosas (29 mulheres) organizadas em quatro subgrupos: i) classe média com idade entre 60 e 74 anos (8); ii) classe média com mais de 75 anos (14); iii) classe baixa com idade entre 60 e 74 anos (8); iv) classe baixa com mais de 75 anos (7). Os principais resultados sugerem que: os aspectos positivos de Aveiro incidem na acessibilidade de alguns edifícios públicos; os aspectos negativos incluem o mau estado dos passeios; a acessibilidade da informação sobre atividades e eventos destaca-se como aspecto positivo e negativo. Os idosos apreciam viver na cidade de Aveiro, mas identificam aspectos que podem ser melhorados para que a cidade proporcione um envelhecimento cada vez mais ativo.

\section{Abstract}

The World Health Organization (WHO) launched the initiative "Age-Friendly Cities" in order to mobilize cities all over the world in the promotion of active ageing. Responding to this challenge, this study tries to understand in what ways is Aveiro (Portugal) an age-friendly city. The methodology adopted the Vancouver Protocol following WHO recommendations. The interview asks the participants to identify positive and negative aspects, as well as suggestions in the following topics: outdoor spaces and buildings; transportation; housing; respect and social inclusion;

\footnotetext{
Universidade de Aveiro. Secção Autônoma de Ciências da Saúde. Mestrado em Gerontologia. Aveiro, Portugal.

2 Universidade de Aveiro. Secção Autônoma de Ciências Sociais, Jurídicas e Políticas. Aveiro, Portugal.

3 Universidade de Aveiro. Secção Autónoma de Ciências da Saúde. Aveiro, Portugal.

Correspondência / Correspondence

Sandra Dias

E-mail: sesdias@gmail.com
} 
social participation; communication and information; civic participation and employment; community support and health services. The interview was administered in focus group to a sample of 37 participants (29 females) divided by four groups: i) middle socio-economic status, 60-74 years (8); ii) middle socio-economic status, 75 years and over; (14); iii) low socio-economic status, 60-74 years (8); iv) low socio-economic status, 75 years and over (7). The main results suggest that: the positive aspects include the accessibility of some public buildings; the negative aspects include poor sidewalk quality; the availability of information about activities and events is underlined both as a positive and a negative aspect. The elderly appreciate living in Aveiro but they identify some aspects that should be improved so that ageing can become more and more active.
Key words: Cities. Ageing. Old Persons. Participation.

\section{INTRODUÇÃOO}

Os fenômenos crescentes e rápidos de urbanização e envelhecimento da população constituem desafios sociais relevantes na atualidade ${ }^{1,2,3,4,5}$. Estima-se que em 2030, três em cada cinco pessoas no mundo habitarão em cidades e que a proporção de idosos (segundo a OMS, indivíduos com mais de 60 anos) residentes em meios urbanos aumentará 16 vezes nos países em desenvolvimento ${ }^{2,3,4}$. Neste contexto, a OMS introduziu a iniciativa Age-Friendly Cities em junho de 2005 (no XVIII World Congress of Gerontology, Rio de Janeiro, Brasil) com o objetivo de mobilizar cidades em todo o mundo para se tornarem mais amigas das pessoas idosas, isto é, promotoras do envelhecimento ativo. Em maio de 2006, ocorreu em Vancouver a reunião inicial das cidades colaboradoras (33 cidades, distribuídas 22 países, incluindo Rio de Janeiro, Istambul, Nova Iorque, Halifax e Londres). Após um programa de investigação desenvolvido entre julho de 2006 e fevereiro de 2007, a OMS 5 produziu o Global Age-Friendly Cities Guide. A transversalidade deste projeto é atestada pela multiplicidade e diversidade de cidades envolvidas, que se distribuem por diferentes continentes, países, sociedades e culturas.

O envelhecimento ativo refere-se ao processo de optimização de oportunidades para a saúde, participação e segurança de modo a aumentar a qualidade de vida durante o envelhecimento, envolvendo múltiplos setores ${ }^{6}$ : saúde, educação, segurança, trabalho, justiça, planejamento e desenvolvimento rural e urbano, habitação, transportes, turismo, tecnologias, cultura e valores sociais e individuais. Deste modo, o envelhecimento ativo também pode ser promovido nas e pelas cidades, se adaptarem estruturas e serviços, de modo a serem acessíveis e inclusos de idosos com diferentes necessidades e capacidades. Ou seja, as cidades devem: prever e responder às necessidades e preferências associadas ao envelhecimento; considerar e respeitar as decisões dos idosos e o estilo de vida que escolheram; promover sua inclusão reconhecendo sua contribuição na comunidade ${ }^{5}$.

Portugal segue a tendência dos restantes países relativamente às mudanças na estrutura etária da população e dos fenômenos de urbanização e despovoação das zonas rurais, em particular a litoralização da população: entre 2000 e 2005, assistiu-se ao reforço da litoralização da população residente, em particular nos territórios metropolitanos ${ }^{7}$. Segundo as Projecções de População Residente para 2008-2060, deverá ocorrer um aumento do número de idosos (em Portugal, indivíduos com mais de 64 anos) relativamente à população total, de 1,847 milhão $(17,4 \%)$ em 2008 para 3,348 milhões (32,3\%) em $2060^{8}$. Torna-se cada vez mais importante identificar as necessidades e desejos desta população, para se criar políticas sociais organizadas, estruturadas e adequadas.

Neste estudo ouvimos a população idosa da cidade de Aveiro (situada na costa atlântica de Portugal), com base nas recomendações do guia age-friendly cities, para compreender como a cidade de Aveiro (Portugal) é ou não amiga das pessoas idosas e, em consequência, perceber sua contribuição para o envelhecimento ativo. 
A cidade de Aveiro

Aveiro situa-se na zona centro de Portugal, no Baixo Vouga, junto à costa atlântica. Apresenta como ex-líbris a Ria de Aveiro, uma laguna com uma área total de $47 \mathrm{~km}^{2}$, que atravessa o centro urbano da cidade ${ }^{9}$. O concelho de Aveiro registava 73.335 habitantes em 2007, 38.116 mulheres e 35219 homens $^{7}$, distribuídos pelas 14 freguesias. Segundo o Inventário Municipal da Região Centro ${ }^{9}$, as freguesias da Glória e Vera Cruz são consideradas de natureza urbana ${ }^{10}$. Assim, este estudo foca essas duas freguesias (figura 1).

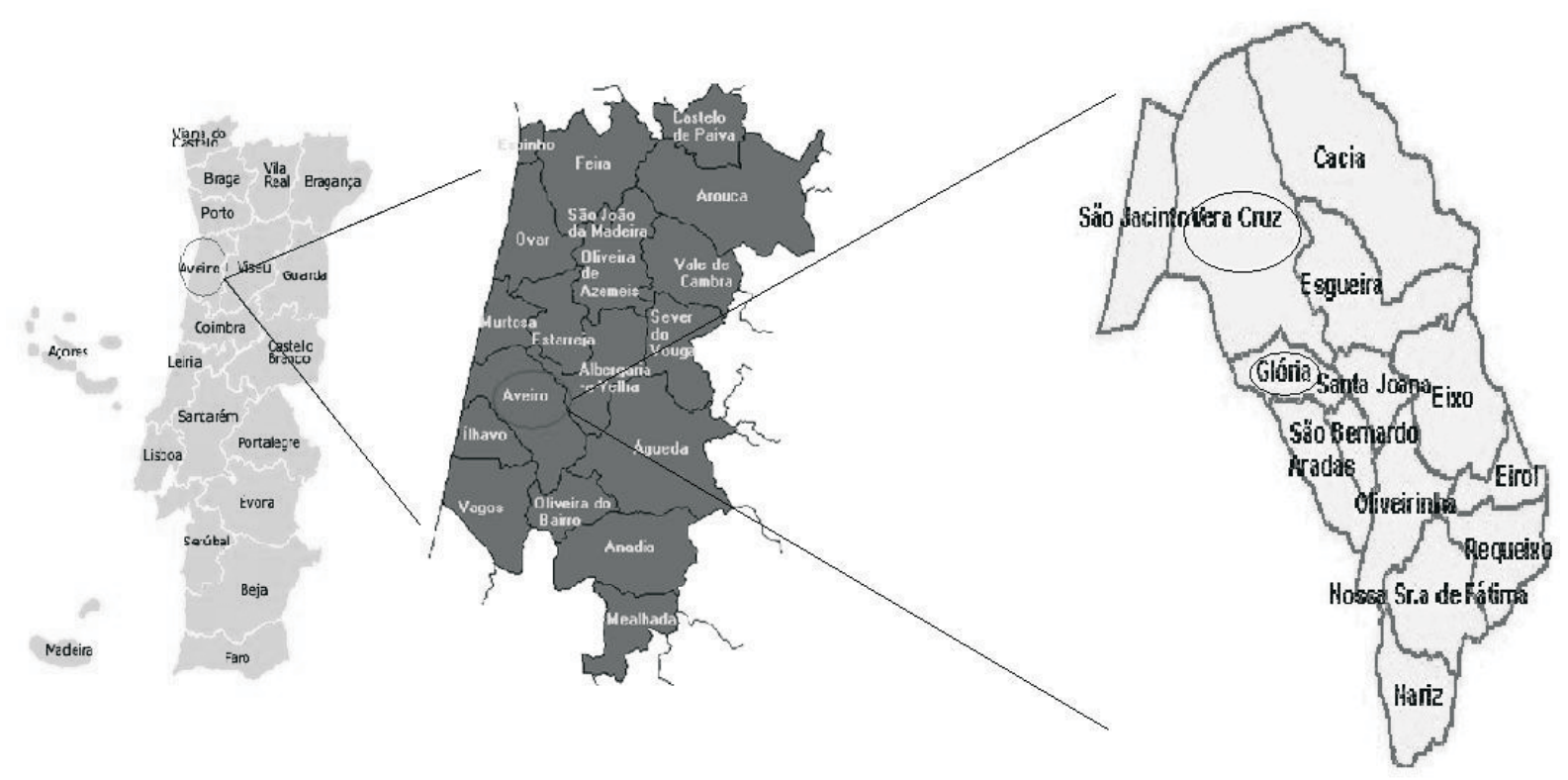

Figura 1. Localização geográfica do distrito de Aveiro, mapa do Concelho de Aveiro e freguesias.

A freguesia da Glória estende-se por $6,87 \mathrm{~km}^{2}$ com 9.917 habitantes, 4601 homens e 5.316 mulheres em $2001^{2,9,11}$, a população idosa representa $15,8 \%$ da população total, ou seja, 1.567 indivíduos ${ }^{11}$. A freguesia de Vera Cruz apresenta uma área total de $38,48 \mathrm{~km}^{2}$ com 8.652 residentes em 2001' 3969 homens e 4.683 mulheres $^{9,11}$; a população idosa representa $16,7 \%$ da população total, isto é 1.445 indivíduos $^{11}$.

\section{METODOLOGIA}

Como este estudo adota os princípios metodológicos da iniciativa Age-friendly Cities, todos os procedimentos seguem o Protocolo de Vancouver ${ }^{12}$.

Constituição e caracterização da amostra

O protocolo define que os participantes tenham idade igual ou superior a 60 anos. Além disso, é necessário identificar a classe social predominante nas freguesias de residência, que, no caso de Aveiro, inclui as duas freguesias urbanas (Glória e Vera Cruz). A freguesia da Glória é classificada como de classe baixa ${ }^{10}$, por isso os idosos residentes nesta freguesia constituem os grupos de classe baixa. A freguesia de Vera Cruz está classificada como classe média ${ }^{10}, \log 0$ os idosos aqui residentes representam essa classe.

Dados mais recentes disponíveis para este nível geográfico. 2009. 
Para seleccionar os participantes, foram identificadas e contactadas instituições sóciocomunitárias, para verificar se a população que as frequentava preenchia os critérios. Em sequência, solicitou-se autorização para realizar o estudo a quatro instituições, que foi concedido. Essas instituições foram escolhidas pela sua abrangência territorial na cidade, de modo a representarem diferentes respostas à população idosa e por isso abrangerem utentes com diferentes características sociais e educativas. Essas instituições incluem: dois Centros de Dia/ Convívio, um situado na Glória e outro na Vera Cruz; uma Universidade Sênior localizada na Vera Cruz; e uma associação recreativa abrangendo a Glória (única instituição cuja população alvo inclui não-idosos, embora para a amostra apenas tenham sido convidados participantes com 60 anos ou mais).

Em seguida, os investigadores explicaram aos utentes o objetivo do estudo, metodologia e colaboração pretendida e os critérios de inclusão (apresentar discurso coerente, estar orientado no tempo e no espaço). Às pessoas que correspondiam a esses critérios e concordaram em participar, entregou-se uma folha com as "questões prévias aos participantes”, para que pudessem ir refletindo sobre cada tópico, de forma a tornar as sessões mais rentáveis.

A amostra compreende 37 pessoas idosas distribuídas por quatro grupos (quadro 1): grupo A (GA), oito participantes com idade entre os 60 e 74 anos, residentes na freguesia de classe baixa (Glória); grupo B (GB), sete participantes com idade igual ou superior a 75 anos residentes na freguesia de classe baixa (Glória); grupo C (GC), 14 participantes com idade igual ou superior a 75 anos residentes na freguesia de classe média (Vera Cruz); grupo D (GD), oito participantes com idade entre os 60 e 74 anos residentes na freguesia de classe média (Vera Cruz).

A média etária dos participantes do grupo A e $D$ é de cerca de 66 anos e a do grupo $\mathrm{B}$ e $\mathrm{C}$, de cerca de 81 anos (quadro 1). Em relação ao gênero, o GA apenas compreende homens e os outros grupos incluem apenas mulheres. Em geral, as habilitações acadêmicas são baixas (56,7\% nunca frequentaramu a escola ou frequentaram a escola primária), contudo $10,8 \%$ fizeram o ensino secundário e $27 \%$ detêm uma licenciatura. A autoavaliação do estado de saúde revela que $43,2 \%$ caracterizam como fraca. Relativamente à habitação, 56,8\% possuem casa própria e $43,2 \%$ vivem com o cônjuge. 
Quadro 1. Caracterização da Amostra. Aveiro, Portugal. 2009.

\begin{tabular}{|c|c|c|c|c|c|c|c|c|c|c|}
\hline & \multicolumn{2}{|c|}{$\begin{array}{c}\text { GA }(\mathrm{n}=8) \\
60-74 \text { anos } \\
\text { Classe Baixa } \\
\text { Glória }\end{array}$} & \multicolumn{2}{|c|}{$\begin{array}{c}\text { GB }(n=7) \\
\geq 75 \text { anos } \\
\text { Classe Baixa } \\
\text { Glória }\end{array}$} & \multicolumn{2}{|c|}{$\begin{array}{c}\text { GC }(\mathrm{n}=14) \\
\geq 75 \text { anos } \\
\text { Classe Média } \\
\text { Vera Cruz }\end{array}$} & \multicolumn{2}{|c|}{$\begin{array}{c}\text { GD }(\mathrm{n}=8) \\
60-74 \text { anos } \\
\text { Classe Média } \\
\text { Vera Cruz }\end{array}$} & \multicolumn{2}{|c|}{ Total $(\mathrm{n}=37)$} \\
\hline & $M$ & $D P$ & $M$ & $D P$ & $M$ & $D P$ & $M$ & $D P$ & $M$ & $D P$ \\
\hline \multirow[t]{2}{*}{ Idade } & 66,4 & 5,0 & 81,9 & 5,9 & 81 & 3,9 & 65,3 & 3,3 & 74,7 & 8,9 \\
\hline & $n$ & $\%$ & $n$ & $\%$ & $n$ & $\%$ & $n$ & $\%$ & $n$ & $\%$ \\
\hline \multicolumn{11}{|l|}{ Sexo } \\
\hline Feminino & 0 & 0 & 7 & 100 & 14 & 100 & 8 & 100 & 29 & 78,4 \\
\hline Masculino & 8 & 100 & 0 & 0 & 0 & 0 & 0 & 0 & 8 & 21,6 \\
\hline \multicolumn{11}{|c|}{ Habilitações literárias } \\
\hline Não frequentou & 0 & 0 & 4 & 57,1 & 2 & 14,3 & 0 & 0 & 6 & 16,2 \\
\hline Até 4 anos & 0 & 0 & 2 & 28,6 & 12 & 85,7 & 1 & 12,5 & 15 & 40,5 \\
\hline 4 a 9 anos & 1 & 12,5 & 1 & 14,3 & 0 & 0 & 0 & 0 & 2 & 5,4 \\
\hline Ensino Secundário & 3 & 37,5 & 0 & 0 & 0 & 0 & 1 & 12,5 & 4 & 10,8 \\
\hline Ensino superior & 4 & 50 & 0 & 0 & 0 & 0 & 6 & 75 & 10 & 27,0 \\
\hline \multicolumn{11}{|c|}{ Percepção do estado de saúde } \\
\hline Fraco & 1 & 12,5 & 6 & 85,7 & 9 & 64,3 & 0 & 0 & 16 & 43,2 \\
\hline Razoável & 0 & 0 & 1 & 14,3 & 5 & 35,7 & 3 & 37,5 & 9 & 24,3 \\
\hline Bom & 7 & 87,5 & 0 & 0 & 0 & 0 & 5 & 62,5 & 12 & 32,4 \\
\hline \multicolumn{11}{|l|}{ Habitação } \\
\hline Própria & 7 & 87,5 & 4 & 57,14 & 5 & 35,7 & 5 & 62,5 & 21 & 56,8 \\
\hline Arrendada & 1 & 12,5 & 2 & 28,57 & 5 & 35,7 & 3 & 37,5 & 11 & 29,7 \\
\hline Do filho & 0 & 0 & 1 & 14,28 & 2 & 14,3 & 0 & 0 & 3 & 8,1 \\
\hline Instituição & 0 & 0 & 0 & 0 & 2 & 14,3 & 0 & 0 & 2 & 5,4 \\
\hline \multicolumn{11}{|c|}{ Composição do agregado familiar } \\
\hline Sozinho & 1 & 12,5 & 5 & 71,4 & 5 & 35,7 & 1 & 12,5 & 12 & 32,4 \\
\hline Cônjuge & 5 & 62,5 & 0 & 0 & 4 & 28,6 & 7 & 87,5 & 16 & 43,2 \\
\hline Cônjuge e filho(s) & 2 & 25 & 0 & 0 & 0 & 0 & 0 & 0 & 2 & 5,4 \\
\hline Com filho(s) & 0 & 0 & 1 & 14,3 & 3 & 21,4 & 0 & 0 & 4 & 10,8 \\
\hline Outros & 0 & 0 & 1 & 14.3 & 2 & 14,3 & 0 & 0 & 3 & 8,1 \\
\hline
\end{tabular}

Instrumento e recolha dos dados

O instrumento de recolha de dados é o guia de entrevista em grupo focal proposto no protocolo de Vancouver, validado para a língua Portuguesa pelos autores através da confrontação de juízes independentes (anexo 1).

A entrevista abrange oito tópicos: espaços exteriores e edifícios; transportes; habitação; respeito e inclusão social; participação social; comunicação e informação; participação cívica e emprego; apoio comunitário e serviços de saúde. Os participantes devem referir aspectos positivos e negativos e apresentar sugestões.
Estes tópicos abrangem as dimensões relevantes para a vida de uma cidade ${ }^{5}$ i) ambiente físico (espaços exteriores e edifícios, transportes e habitação), com influência na mobilidade individual, proteção contra os danos físicos e segurança contra o crime; ii) participação social e cultural, que afeta a participação e o bem-estar (inclui: respeito e inclusão social relacionados com as atitudes e comportamentos dos outros em relação aos mais velhos; participação social em atividades recreativas, culturais, educativas e espirituais; participação cívica e emprego referente às condições de cidadania e trabalho remunerado e não remunerado, associados aos determinantes econômicos do envelhecimento ativo); iii) 
ambiente social e determinantes da saúde e ação social (envolve comunicação e informação, apoio comunitário e serviços de saúde).

Esse guia de entrevista foi aplicado em grupos focais, moderados por dois coordenadores (autores). No início da primeira sessão de cada grupo, era assinado o consentimento livre e informado e preenchidos os questionários com os dados sócio-demográficos. Os grupos focais realizaram-se entre 12 de fevereiro e 26 de março de 2009, nas instituições que colaboraram no estudo. Cada grupo focal foi organizado em duas sessões (cada com duração aproximada de 90 minutos), de acordo com a disponibilidade dos participantes; foi decidido ter duas sessões pelo fato de o guia ser longo, sendo esta a forma de garantir que os participantes dariam igual atenção a todos os tópicos sem ficarem cansados.

\section{Análise dos dados}

As entrevistas foram gravadas, transcritas e submetidas à análise de conteúdo. A análise desenrolou-se em dois momentos: i) número de vezes que cada tópico foi mencionado (quadro 2); ii) descrição das opiniões dos participantes por tópico.

Quadro 2. Tópicos, aspectos positivos, negativos e sugestões: número de referências por grupo de participantes. Aveiro, Portugal. 2009.

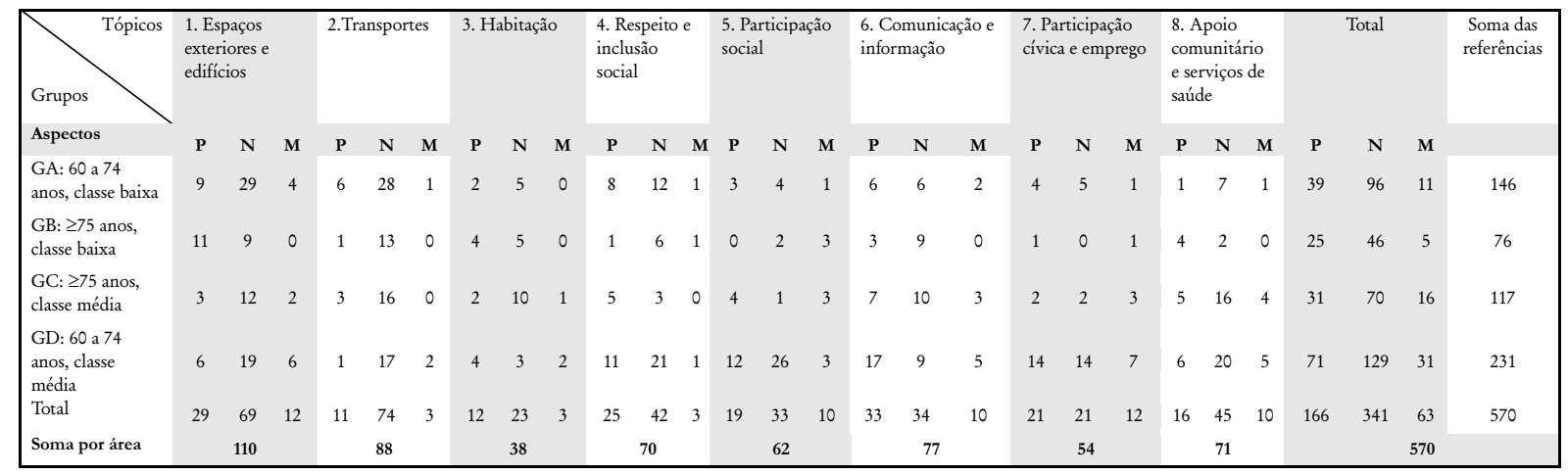

$\mathrm{P}$ - Aspectos positivos; $\mathrm{N}$ - Aspectos negativos; $\mathrm{M}$ - Sugestões

\section{Ética na pesquisa}

A instituição promotora (Universidade de Aveiro) não tem Comissão de Ética, pois tal ainda não é exigido no país (Portugal), mas está assegurado o cumprimento das regras de ética através da autorização das instituições participantes e da assinatura do consentimento livre e informado.

\section{RESULTADOS}

Os dados denotam que os grupos diferem nas suas opiniões (quadro 2): o GD é mais opinativo, seguindo-se o GA (estes dois grupos incluem pessoas idosas mais novas, com mais habilitações acadêmicas, que frequentam instituições recreativas e revelam uma percepção de bom estado de saúde); o GB é o que faz menos referências, seguindo-se o GC (estes grupos apresentam idade superior, frequentam instituições sociais, apresentam baixas habilitações acadêmicas e avaliam o estado de saúde como fraco). Este dado parece indicar os diferentes níveis de participação e iniciativa da população idosa em Aveiro.

Em geral (quadro 2), verifica-se que são mencionados mais aspectos negativos (341), relativamente aos positivos (166). Contudo, as sugestões de melhoria são relativamente poucas (63), podendo indicar que os idosos sentem ter 
poucos conhecimentos para fazer sugestões ou sentem pouca confiança nas suas opiniões.

Em termos dos tópicos, os mais referidos centram-se no ambiente físico (espaços exteriores e edifícios, transportes), com exceção da habitação, que é o tópico menos referido (os participantes consideram a habitação como responsabilidade individual). Seguem-se os tópicos associados ao ambiente social (comunicação e informação, apoio comunitário e serviços de saúde). Os menos referidos referem-se à participação social e cultural (respeito e inclusão social, participação social, participação cívica e emprego).

Os principais aspectos negativos centram-se em espaços exteriores e edifícios e transportes (ambiente físico), enquanto os positivos focam comunicação e informação, espaços exteriores e edifícios e respeito e inclusão social.

Passamos à análise mais descritiva por tópico

Os espaços exteriores e edificicios públicos são essenciais para a mobilidade e independência funcional. Os principais aspectos positivos centram-se na acessibilidade de alguns edifícios públicos, nomeadamente: Registo Predial, Correios e Hospital.

\section{"As unidades de saúde têm acessibilidade e os correios também. Se forpreciso uma rampa para uma cadeira de rodas não há problema". [GB, 79 anos, mulher]}

Os aspectos negativos mais referidos focam o mau estado dos passeios, que, segundo os participantes, levam muitos idosos a evitar sair de casa, com medo de quedas. Também salientam a falta de manutenção dos espaços verdes e reduzido número de zonas de repouso, que limita as opções de ocupação dos tempos livres.

"Passeioséburaquinhos, éburacões... ospasseios são ladrilhos e as árvores levantam os ladrilhos, umapessoa vai nopasseio e cail'"[GA, 66 anos, homem]

Os participantes sugerem que se pode melhorar com arranjo dos passeios, criação de mais espaços verdes e zonas de repouso. Esta é uma forma de incentivar a prática de atividades de lazer ao ar livre pelos idosos.

Os transportes são essenciais na mobilidade citadina, influenciando a participação social e cívica e o acesso aos serviços comunitários. $\mathrm{O}$ aspecto positivo mais referido é a segurança e confiança na utilização dos transportes públicos.

"Nos autocarros nunca senti perigo de ser assaltado...!'[GA, 65 anos, homem]

O aspecto negativo mais mencionado é a difícil acessibilidade na entrada e saída dos autocarros, que condiciona o seu uso e a mobilidade dos idosos. Contudo, os participantes tendem a atribuir essa falta de acessibilidade às suas limitações físicas, não vislumbrando soluções, pois desconhecem as técnicas de acessibilidade.

\section{"Tenho de ir sempre com uma pessoa porque estou muito mal das pernas, não posso subir nem descer do autocarro porque é muito alto!" [GB, 79 anos, mulher]}

Os participantes sugerem uma maior rentabilização do parque de estacionamento $\mathrm{da}$ cidade de forma a melhorar a circulação automóvel.

\section{'Deviam tornar oparque de estacionamento na baixa mais acessivel para que as pessoas não tivessem que estacionar em segunda fila." [GD, 61 anos, mulher]}

A babitação é determinante na independência dos idosos. $\mathrm{O}$ aspecto positivo mais referido foi a adaptação da casa (recurso a ajudas técnicas) para as limitações funcionais que tendem a ocorrer com o envelhecimento (por exemplo, dificuldade em utilizar a banheira e subir escadas), que alguns entrevistados já utilizaram nas suas habitações.

Os aspectos negativos mais salientados foram: elevados custos da habitação, pois a mão-de-obra de alguns profissionais é escassa e cara; e a insegurança física na habitação (inclui fatores precipitantes de quedas, tais como pisos escorregadios), agravada para quem vive só. 
"Tenho medo de cair em casa, já cai muitas vezes. Hápouco tempo, tive de irpara o hospital...!'[GB, 75 anos, mulher]

As sugestões incidem na possibilidade das entidades públicas apoiarem os idosos com fracos rendimentos em pequenas reparações na habitação.

"O município podia disponibilizar serviços gratuitos a idosos compoucos rendimentos. Por exemplo, uma janela empenada, ...!'[GD, 61 anos, mulher]

O respeito e a inclusão social dos idosos são influenciados pela cultura, gênero, estado de saúde, situação financeira e transformações sociais. Os participantes tendem a dar poucas sugestões, pois consideram que saber respeitar é algo com que se nasce e não se modifica ao longo da vida (ou se tem ou não se tem). $\mathrm{O}$ aspecto positivo mais referido é a consideração da opinião dos idosos em tomadas de decisão.

"O município tem sessões abertas à comunidade. E agora mudaram para a tarde para dar a possibilidade depessoas idosaspoderem assistir. "[GA, 70 anos, homem]

O aspecto negativo mais referido é a falta de delicadeza e educação da sociedade perante os mais velhos.

"No domingo na missa, chegou uma senhora idosa de canadianas e não tinh a lugar; nenhum jovem se levantou; foi um senhor mais velho que deu o lugar!" [GC, 76 anos, mulher]

As sugestões incidem no reconhecimento pelo Estado do contributo dos idosos para a comunidade.

"Acho que o reconhecimento devia ser governamental, principalmente para esses idosos que recebem com uns miseros 300 euros, que não chega para comer $e$ comprar os medicamentos!" [GD, 65 anos, mulher]

$\mathrm{Na}$ participação social, incluem-se as atividades que possibilitam aos idosos manter/melhorar as suas competências, relações de apoio e afeto. $\mathrm{O}$ aspeto positivo mais referido é a variedade de atividades disponíveis na cidade, que atendem à heterogeneidade da comunidade idosa aveirense e facilitam a sua participação.

"Actividades culturais, há bastantes! Não nos podemos queixar, há teatro, cinema, bailado, música." [GD, 69 anos, mulher]

$\mathrm{O}$ aspecto negativo mais mencionado foi o elevado preço das atividades, que pode restringir o acesso dos idosos com menos recursos. Os participantes sugerem uma oferta cada vez mais diversificada, com menor custo de forma incluir todos os idosos, independentemente dos interesses e recursos econômicos.

A comunicação e a informação são fundamentais para que os idosos conheçam a realidade envolvente, inclui: atividades, eventos e notícias da cidade. $\mathrm{O}$ principal aspecto positivo é a acessibilidade da informação, que constitui também o principal aspecto negativo e a essencial sugestão de melhoria. Isto ocorre principalmente porque: i) os dois grupos de pessoas com 75 anos ou mais (GB e GC) referem mais aspectos negativos; ii) os dois grupos entre os 60 e os 74 anos (GA e GD) referem mais aspectos positivos; iii) todos os grupos apresentam sugestões.

"Falam nos jornais e no boletim municipal. Mas devia haver mais placares naqueles sitios aonde as pessoas idosas vão!’[GA, 74 anos, homem]

A participação civica e e emprego podem constituir estratégias para manter a contribuição dos idosos na comunidade. Os principais aspectos positivos centram-se nas experiências de voluntariado e na diversidade de áreas para essa prática. Diversos idosos estão envolvidos em voluntariado em igrejas e lares de idosos.

"Sou voluntária bá 10 anos, num lar da terceira idade! É uma oportunidade fantástica, fazer voluntariado em vez de estar em casa a apanhar neura."[GD, 70 anos, mulher]

O aspecto negativo mais referido é a inexistência de oportunidades de trabalho remunerado; contudo, consideram que os mais velhos não devem tirar o emprego aos mais jovens, pois já são reformados. 
As sugestões referem-se à diversificação dos projetos de voluntariado, nomeadamente no apoio a pessoas idosas que vivem sozinhas e com fracos recursos econômicos.

O apoio comunitário e serviços de saúde são fundamentais para os cuidados de saúde e independência dos idosos. Os participantes enunciaram como principal aspecto positivo o fato de os serviços de saúde e apoio domiciliário responderem às suas necessidades.

"Se precisarmos, podemos pedir análises, radiografias...medem-nos a tensão, tratam-nos os pés, pintam-nos as unbas...!" [GC, 75 anos, mulher]

O principal aspecto negativo centra-se na inexistência de um lar no centro da cidade; as respostas sociais localizam-se na periferia, dificultando a visita dos familiares e amigos e fazendo o idoso sentir-se deslocado. Sugerem a redução do preço dos cuidados de saúde, referindo que as pessoas com escassos rendimentos deveriam ter direito a consultas de especialidade gratuitas, assim como ajudas técnicas e lares acessíveis economicamente.

\section{DISCUSSÃO}

Os participantes percepcionam Aveiro como uma cidade em que os idosos apreciam viver, salientando a sua beleza natural e relevo plano. Os participantes apontam aspectos positivos em todos os tópicos, mas referem mais aspectos negativos (do que positivos). Em investigação, tem-se observado que, em geral, os participantes têm mais facilidade em referir aspectos negativos, pois o que está bem (positivo) é tomado como garantido e não causa estresse ${ }^{13}$. Para além disto, a Cidade de Aveiro (como a maioria das cidades um pouco por todo o mundo) tem dado pouca atenção às necessidades específicas dos mais velhos. Provavelmente, porque o envelhecimento da população e a sua centração em zonas urbanas é um fenômeno recente, embora de rápido desenvolvimento, que surpreendeu as autoridades locais. Assim, Aveiro tem de investir no processo de ser cada vez mais amiga dos seus cidadãos mais idosos.

O principal elemento positivo é o fácil acesso à informação, o que constitui fator fulcral para a resposta adequada às necessidades individuais. Mas este aspecto se destaca também pela negativa. Os dados indicam que os idosos com mais de 75 anos referem mais aspectos negativos e aqueles com idade entre 60 e 74 anos, mais positivos. Isto parece sugerir que a informação é mais acessível a pessoas com mais funcionalidade, que se podem deslocar aos locais onde a informação é disponibilizada (por exemplo, vitrinas). Além disso, estes idosos frequentam mais cafés, onde trocam informação com outras pessoas e lêem o jornal disponibilizado com frequência nesses locais. Os mais velhos, por norma, com mais limitações funcionais, estão mais restritos à sua casa e ao centro de dia/convívio. Assim, parece relevante, por exemplo, que nos centros de dia/convívio existam jornais e também vitrinas de informação sobre a cidade.

Entre os tópicos mais referidos pela negativa, destacam-se os "espaços exteriores e edifícios" e os "transportes". Estas áreas constituem elementos fundamentais do ambiente físico duma cidade, indispensáveis ao envelhecimento ativo. Em diversas cidades (incluindo Himeji, Mayaguez, Melbourne e Nova Deli), foi salientada a importância dos novos edifícios serem acessíveis às características das pessoas idosas ${ }^{5}$. Em Aveiro, já é reconhecida a boa acessibilidade de diversos edifícios públicos; contudo, há muitas referências negativas, principalmente sobre problemas nos espaços públicos de circulação pedonal, um tema transversal partilhado por idosos de Moscovo, Rio de Janeiro, México, La Plata e Ponce 5 .

Os participantes aveirenses recomendam o aumento dos espaços verdes e zonas de repouso, salientando a necessidade de conservação e manutenção.

Quanto aos transportes públicos, referem como principal obstáculo a falta de acessibilidade na entrada e saída dos autocarros (por exemplo, na cidade de Udine é referida a altura dos degraus dos autocarros) $)^{5}$. 
Os dados revelam a heterogeneidade da população idosa aveirense, evidente nas diferentes preocupações e visões da realidade urbana dos grupos de participantes. Sugere-se que a idade, tipo de instituição frequentada, habilitações acadêmicas e percepção do estado de saúde são elementos que influenciam a capacidade de participação e iniciativa dos idosos. Por exemplo, verifica-se que os participantes mais idosos de classe socioeconômica baixa, que frequentam o centro de dia, são menos participativos: indicam menos aspectos positivos, negativos e sugestões. A cidade deve estar atenta aos idosos com menos iniciativa, por norma os mais idosos e/ ou de classe mais baixa.

Os participantes salientaram a necessidade de medidas de apoio (serviços sociais, recreativos e de saúde gratuitos e apoio de voluntariado) para dois grupos de idosos mais vulneráveis: os que vivem sós e/ou apresentam baixos rendimentos. Neste contexto, enfatizam a necessidade de mais e maior variedade de iniciativas de voluntariado a desenvolver por idosos para idosos: oportunidade para responder às necessidades dos que precisam, pelos que querem e podem colaborar.

\section{CONSIDERAÇÕES FINAIS}

A saúde, o bem-estar e o envelhecimento são temas relevantes na sociedade contemporânea, vincados pelos meios de comunicação social, por um crescente número de cidadãos e pela agenda política internacional e nacional. Neste contexto, as populações desenvolvem expectativas para alcançarem patamares mais elevados de qualidade de vida, envolvendo a participação ativa em decisões da comunidade. Este momento constitui uma oportunidade para o desenho de estratégias e intervenções capazes de promover o "viver mais" de forma saudável, independente e ativa, o que beneficia o indivíduo e a comunidade.

Este estudo na cidade de Aveiro (uma cidade pequena) é mais um contributo para a promoção do envelhecimento ativo, pelos resultados obtidos e por dar voz aos mais idosos. Uma das medidas importantes será a manutenção de um grupo de idosos (informantes privilegiados) que sejam ouvidos com regularidade pelas autoridades locais para apoiar as transformações urbanas. Consideramos que o município deve ter um papel relevante, constituindo esse grupo e promovendo reuniões bianuais para discussão.

Este estudo apresenta algumas limitações relacionadas com a amostra: os grupos são homogêneos em relação ao gênero (3 compreendem apenas mulheres e 1 somente homens), o que poderá influenciar os resultados, devido ao relevo das diferenças de gênero na velhice; o tipo de amostragem recorreu à colaboração de instituições comunitárias, o que excluiu idosos sem ligações institucionais. Nesta fase centramo-nos na opinião dos cidadãos idosos, mas afigura-se relevante realizar grupos focais (tal como proposto pela OMS), envolvendo cuidadores de idosos e profissionais que trabalhem direta ou indiretamente com aspectos associados ao envelhecimento.

Emerge como relevante a replicação do estudo noutras cidades Portuguesas para caracterizar os meios urbanos nacionais, avaliando as condições de promoção do envelhecimento ativo e facilitando o intercâmbio de boas práticas entre autoridades locais. 


\section{REFERÊNCIAS}

1. Barca F. Agenda for a Reformed Cohesion Policy: a place-based approach to meeting European Union challenges and expectations. Independent Report prepared at the request of Danuta Hübner, Commissioner for Regional Policy. 2009.

2. Comissão Europeia, Direcção-Geral da Política Regional. As regiões e a mudança econômica: respostas da política regional aos desafios demográficos. Bruxelas: 2007. 24p. Disponível em URL: http://ec.europa.eu/regional_policy/ sources/docgener/presenta/demo/ demochallenge_pt.pdf

3. Comission of the European Communities. Regions 2020: an assessment of future challenges for EU regions. Bruxelas: 2008. 47p. Disponível em URL: http://ec.europa.eu/regional_policy/ sources/docoffic/working/regions2020/pdf/ regions2020_en.pdf

4. Comission of the European Communities. Promoting Sustainable Urban Development in Europe: achievements and opportunities. Bruxelas: 2009. 60p. Disponível em URL: http:// ec.europa.eu/regional_policy/sources/docgener/ presenta/urban2009/urban2009_en.pdf

5. World Health Organization. Global AgeFriendly Cities: a guide. Genebra: 2007. 82p. Disponível em URL: http://who.int/ageing/ publications/ Global_age_friendly_cities_Guide_English.pdf

6. World Health Organization. Active ageing: a policy framework. Genebra: 2002.60p.

Disponível em URL: http://

whqlibdoc.who.int/hq/2002/

WHO_NMH_NPH_02.8.pdf
7. Instituto Nacional de Estatística. Retrato territorial de Portugal 2005. Lisboa: Instituto Nacional de Estatística; 2007. 318p. Disponível em URL: http://www.ine.pt/xportal/ $x$ main'2xpid $=\mathbb{N} E \&$ xpgid $=$ ine publicacoes\&PUBLCACOES pub_boui $=379068 \&$ PUBLICACOES tem $\bar{a}=55466 \&$ PUBLICACOESmodo $=2$

8. Instituto Nacional de Estatística. Projecções População Residente em Portugal 2008-2060; 2009. Disponível em URL: http:// www.ine.pt/ngt_server/ attachfileu.jsp?look_parentBoui $=$ 66023625\&att_display $=$ n\&att_download $=y$

9. Cruz V. Plano de Urbanização da Cidade de Aveiro VII. Aveiro: Câmara Municipal de Aveiro; 2004.

10. Hespanha P, et al. População e Território. In: Hespanha P, et al. Horizontes Sociais. Aveiro: Universidade de Aveiro; 2001. p.11-24.

11. Instituto Nacional de Estatística. Censos 2001. Disponível em URL: http://www.ine.pt/ xportal/ $x$ main? $x p i d=I N E \& x p g i d=$ ine publicacoes\&PUBLICACOESpub boui $=1$ 334118PUBLCACOEStema=CO\&PUBLCACOESmodo=2

12. World Health Organization. Who Age-Friendly Cities Project Methodology: Vancouver Protocol. Genebra: 2007. 26p. Disponível em URL: http://www.saude.sp.gov.br/resources/ profissional/acesso_rapido/gtae/ saude_pessoa_idosa/ protocolo_vancouver_cidade_amiga_do_idoso.pdf.

13. Tripp D. Critical incidents in teaching: developing Professional judgement. $1^{\mathrm{a}}$ edição. Londres: Routledge; 1993. 164p. 
Em todos os tópicos, gostaríamos de conhecer as vossas experiências positivas e negativas e que referissem as vossas ideias para melhorar a situação actual.

\section{Tópico 1. Espaços exteriores e edifícios}

Como é sair de casa para dar um passeio, fazer algum recado ou visitar alguém? Como é entrar em edifícios como serviços públicos ou lojas?

Perguntar por: design e manutenção de passeios e calçadas; cruzamentos e passadeiras da rua; volume de tráfego e ruído; alturas particulares do dia, como a noite; condições climatéricas; espaços verdes, zonas pedonais; iluminação das ruas; protecção do sol, chuva ou vento; bancos e áreas de repouso; sensação de segurança física; sensação de segurança em relação a ser vítima de algum crim; dentro dos edifícios: escadas, portas, elevadores, corredores, pavimentos, iluminação, sinalização, casas de banho, salas de espera.

\section{Tópico 2. Transportes}

Descrevam a vossa experiência enquanto utilizadores dos transportes públicos (autocarro, comboio, metro, ...), e enquanto condutores na vossa comunidade.

Perguntar acerca dos transportes públicos: preço acessível; proximidade das paragens; facilidade de entrar; frequência de passagem; pontualidade; percursos/rotas; paragens com bancos, luz e protecção do tempo (vento, chuva ou sol); segurança em relação ao crime; adaptações para pessoas com incapacidades.

Perguntar aos condutores por: sinais de trânsito legíveis; números das ruas legíveis; iluminação nos cruzamentos e entroncamentos; sinais de trânsito fáceis de entender; estacionamentos suficientes, próximos e reservados para pessoas com deficiência; lugares para largar e apanhar pessoas; cursos de actualização/renovação para condutores.

\section{Tópico 3. Habitação}

Falem-nos do apartamento ou casa em que vivem? Se as vossas necessidades se alterarem, quais são as escolhas de alojamento que a comunidade pode oferecer?

Perguntar por: aceitabilidade; custo; conforto; segurança física; segurança em relação ao crime; proximidade dos serviços; mobilidade em casa; facilidade em arrumar e chegar aos objectos; realização das tarefas domésticas.

\section{Tópico 4. Respeito e inclusão social}

De que forma a comunidade demonstra ou não respeito por vós enquanto pessoas idosas? De que forma a comunidade vos inclui enquanto pessoas idosas nas actividades e eventos?

Perguntar por: delicadeza e educação; disponibilidade para escutar; prestação de auxílio; capacidade de resposta às necessidades através de serviços ou programas; consulta na tomada de decisões; escolhas oferecidas; reconhecimento público do contributo das pessoas idosas; actividades intergeracionais. 


\section{Tópico 5. Participação social}

Têm facilidade em conviver na vossa comunidade? Falem-nos sobre a vossa participação noutras actividades, como: actividades recreativas, culturais, espirituais/religiosas?

Perguntar acerca das actividades sociais e de lazer: preço acessível; acesso; frequência; localização e horário conveniente; oferta variada; interesse.

\section{Tópico 6. Comunicação e informação}

$\mathrm{Na}$ vossa comunidade têm acesso à informação que necessitam, por exemplo sobre serviços ou eventos? Podem conseguir esta informação por telefone, rádio, televisão, imprensa escrita ou pessoalmente?

Perguntar por: acessibilidade; utilidade, compreensão; dificuldades na utilização de sistemas automatizados, formato e tamanho da publicação.

\section{Tópico 7. Participação cívica e emprego}

Falem-nos da vossa participação em voluntariado? Falem-nos da vossa participação em trabalho remunerado; se actualmente estão empregados ou à procura de trabalho remunerado? Falem-nos da vossa participação em assuntos públicos comunitários, como associações comunitárias, ou município/ junta de freguesia?

Perguntar por: disponibilidade da informação; oportunidades acessíveis; variedade de oportunidades; atractividade; reconhecimento; remuneração (trabalho remunerado); ajustamento às capacidades e/ ou competências das pessoas idosas; ajustamento às preferências; formas usadas para motivar a participação de pessoas idosas.

Tópico 8. Apoio comunitário e serviços de saúde

Qual a vossa experiência com os serviços comunitários que apoiam as pessoas idosas?

Perguntar por: serviços disponíveis; acessibilidade; preço; resposta dos serviços às necessidades individuais.

Pergunta de finalização - Antes de acabarmos, gostaríamos de saber se existem outros assuntos ou áreas que não discutimos e que queiram abordar? 
